\title{
Nocturia: a blinded, randomized, parallel placebo-controlled self-study of the effect of 5 different sedatives and analgesics
}

\author{
Michael Kaye, MB BS, FRCPC
}

See related article on page 609

\section{Abstract}

Background: In a previous study I noted that, when taken occasionally as a nighttime sedative, the benzodiazepine (BZD) oxazepam decreased nocturia. The objective of the present study was, using placebo and other sedatives and analgesics, to assess whether oxazepam decreases nocturia and, if so, how?

Methods: I conducted a prospective, randomized, placebo-controlled self-study over a period of 10 months using oxazepam, zopiclone and trazodone as sedatives, and naproxen and oxycodone as analgesics. I assessed each medication 10 times, for a total of 60 tests. Each test included assessment of sleep adequacy, number and volume of overnight voidings and chemistries. Every test was a "first-time" or "naive" event.

Results: All medications differed in several parameters from placebo, but nocturia only showed a significant reduction with naproxen and oxazepam. Nocturia occurred a mean (standard deviation [SD]) of $1.6(0.84)$ times nightly with placebo and fell to 0.6 (0.5) with oxazepam, which was a $63 \%$ decrease without any change in urine volume. Naproxen reduced nocturia to a mean (SD) of $0.7(0.8)$ times nightly by reducing water, salt and potassium excretion. Compared with placebo, all medications had less urine sodium loss and decreased fractional sodium excretion (FENa), suggesting increased renal tubular sodium reabsorption. This effect was most marked with naproxen. Neither improved sleep quality with zopiclone nor pain relief with oxycodone resulted in reduced nocturia.

Conclusion: The effect of naproxen was probably a direct one on the kidney. The reduction of electrolyte excretion produced by the other medications is possibly a central effect on sympathetic activity, and the effect was too small to change urine volume. The effect of oxazepam was to make the bladder less irritable and could not be attributed to a decrease in urine volume, electrolyte change, sedation or analgesia. A central $\gamma$-aminobutyric acid-mediated effect in the cord or brain could explain the results observed with oxazepam.

Can Urol Assoc J 2008;2(6):604-8

\section{Introduction}

Nocturia, defined as awakening 1 or more times at night owing to the urge to void, ${ }^{1}$ is more common in older men and women, and the night urine contains a greater fraction of the 24-hour sodium excretion compared with that of younger adults.,.$^{2,3}$ sually there are no structural abnormalities in the urinary tract, or if some, such as prostatic hypertrophy, are present they are not responsible for the symptom. ${ }^{4}$

By chance, I noted that when the functionally short-acting benzodiazepine (BZD) oxazepam (the $\mathrm{N}$-demythylated 3 hydroxylated metabolic product of diazepam), ${ }^{5}$ was occasionally taken for nighttime sedation, nocturia was reduced. In a previous study (unpublished data, 2003), this effect was tested in an open setting without placebo. Nocturia decreased from a mean (standard deviation [SD]) of $1.2(0.6)$ to $0.4(0.5)$ times nightly $(n=9, p<0.010)$ and was associated with decreased sodium excretion. Subsequently, we became aware of a previous study ${ }^{6}$ where diazepam had been used to decrease nocturia. The authors believed it acted by improving quality of sleep.

I designed the present study to examine this effect more carefully and to compare oxazepam with the closely related non-BZD sedative zopiclone, which also acts by binding to the $\gamma$-aminobutyric acid type $A$, $\left(\mathrm{GABA}_{\mathrm{A}}\right)$ receptor. $^{7}$ In addition, I included 2 analgesics, naproxen (a nonsteroidal antiinflammatory) and oxycodone (an opioid), which is twice as potent as morphine on a weight basis. ${ }^{8}$ Finally, I added the sedative/ antidepressant trazodone, ${ }^{9}$ which binds to 5-hydroxytryptamine and adrenergic receptors, and conducted a blinded, randomized self-study. This methodology has been validated previously. ${ }^{10}$

\section{Methods}

I am a white man whose laboratory and behavioural characteristics were established in several studies ${ }^{11}$ during the 2 years preceeding the present study. At the time of study, I was 77 years old, weight was stable at $65 \mathrm{~kg}$, body mass index was $22.8 \mathrm{~kg} / \mathrm{m}^{2}$ and medications had been unchanged for several years. Medications included $5 \mathrm{mg} / \mathrm{d}$ of finasteride, $12.5 \mathrm{mg} / \mathrm{d}$ of chlorthalidone, $40 \mathrm{mg}$ of sotalol twice daily and $100 \mathrm{mg} / \mathrm{d}$ of losarten. History included 
prostatic hypertrophy and hypertension, both controlled with treatment. Prostate size was 30 g, as estimated by a senior urologist, and blood pressure was between 110/65 and 120/70 mm Hg. Symptoms were nocturia once or twice nightly, urgency and, rarely, urge incontinence.

To ensure blinding, a pharmacist provided pills for the study in brown opaque sealed \#1 coin envelopes measuring $2.2 \times 3.5$ inches. Thirty minutes before reclining for sleep, the top was cut off and the envelope placed in the mouth so that the single pill inside fell on the tongue and was washed down with several sips of water without having been seen or identified. Placebo was coated sugar, and medications were $15 \mathrm{mg}$ of oxazepam; $5 \mathrm{mg}$ of zopiclone; $500 \mathrm{mg}$ of naproxen; $5 \mathrm{mg}$ of oxycodone, immediate release; and $50 \mathrm{mg}$ of trazodone. The bladder was emptied before retiring and the urine discarded. I measured and saved subsequent urine until rising the following morning; the bladder was emptied again to complete the night collection. I coded sleep quality as bad (1), indifferent (2) or good (3).

The medications were randomized in blocks of 6 ( 5 active drugs plus placebo), the envelopes were labelled 1-60 and adjusted so that the same medication could not be taken at the end of one block and the beginning of the next. There was a minimum of 72 hours between tests and, because the same drug was not taken consecutively, there would usually be 1 week or more before the drug was repeated. The aim was to have the equivalent of a first-time exposure for every test. Each medication was taken 10 times for a total of 60 tests between October 2004 and June 2005. Only the test number was known and the code was not broken until the study was completed.

Following each night's collection, the urine was mixed and a $5 \mathrm{~mL}$ aliquot was frozen. After completion of the study, all collections were analyzed as a single batch in September 2005 at the Montreal General Hospital Clinical Chemistry Laboratories using a Hitachi 9.7 analyzer. Osmolality was measured in duplicate on a Fiske osmometer. I provided 5 blood samples at intervals between September 2005 and May 2006. Each was analyzed the same day. The results were all in the normal range and within experimental error. Before the study, blood had been analyzed at 9 am and $9 \mathrm{pm}$ on 2 consecutive days, ${ }^{11}$ yielding similar values. Therefore, mean values for serum creatinine, sodium and osmolality from the samples obtained during the study period were used to calculate the derived values of fractional sodium excretion (FENa), creatinine and osmolar clearances according to standard formulae. ${ }^{12}$

I entered the data in Excel (Microsoft Corp.) spreadsheets and analyzed them using the statistical routines. Results are shown as mean (SD). I evaluated the differences between medications using multivariate regression with $p<0.05$ as the threshold of statistical significance. ${ }^{13}$

\section{Results}

Perfect sleep scores (3 for every night) were achieved with oxazepam and zopiclone only

Table 1. Summary of findings from self-study, by treatment type*

\begin{tabular}{|c|c|c|c|c|c|c|}
\hline \multirow[b]{2}{*}{ Characteristic } & \multicolumn{6}{|c|}{ Treatment, mean (SD)† } \\
\hline & Placebo & Oxazepam & Zopiclone & Naproxen & Oxycodone & Trazodone \\
\hline Sleep score & $2.5(0.9)$ & $3.0(0.0)$ & $3.0(0.0)$ & $2.7(0.7)$ & $2.7(0.5)$ & $2.2(0.8)$ \\
\hline Hours in bed & $8.4(0.6)$ & $8.7(0.6)$ & $8.3(0.6)$ & $8.2(0.4)$ & $8.6(0.5)$ & $8.6(0.8)$ \\
\hline $\begin{array}{l}\text { Urine volume, } \\
\mathrm{mL}\end{array}$ & $666(261)$ & $590(170)$ & 641 (176) & $358(202) \emptyset$ & $520(139)$ & $504(192)$ \\
\hline $\begin{array}{l}\text { Nocturia-free } \\
\text { nightsł }\end{array}$ & 1 & 4 & 0 & 5 & 2 & 1 \\
\hline $\begin{array}{l}\text { Max void } \\
\text { volume, } \$ \mathrm{~mL}\end{array}$ & 425 & 450 & 450 & 400 & 400 & 425 \\
\hline \multicolumn{7}{|c|}{$\begin{array}{l}\text { *Ten tests were performed with each treatment, for a total of } 60 \text { tests. } \\
\text { †Unless otherwise indicated. } \\
\text { ¥Nocturia-free nights out of a possible maximum of } 10 \text {. } \\
\text { §Max void volume is the maximum nocturnal volume of any voiding for this drug. } \\
\uparrow p<0.05 \text { when compared with placebo. }\end{array}$} \\
\hline
\end{tabular}


(Table 1); however, the differences between the medications were small and nonsignificant. Total urine volume was highest with placebo, but the difference in volume with the other medications was significant with naproxen only. However, when expressed in millilitres per minute, the volumes with both naproxen and trazodone were different from that with placebo (Table 2).

With all drugs there was less nocturia than with placebo, but only for oxazepam and naproxen was the effect marked enough to achieve significance. Maximum void volume did not differ among medications and was usually less than the total night volume.

Urine chemistries were most changed for naproxen (Table 2). It differs from the other drugs in the intensity of the effect, yet findings with all medications show less electrolyte loss than with placebo, particularly in sodium excretion and the percentage of filtered sodium that appears in the urine $(\mathrm{FENa} \%)$. Potassium loss was reduced with oxazepam, naproxen and oxycodone. Glomerular filtration, as approximated by creatinine clearance, was similar among all medications and placebo, and osmolalities varied considerably but were not significantly different from one another. The osmolar clearance (the number of osmotically active particles excreted per minute divided by the plasma osmolality) was decreased with naproxen and, to a lesser extent, with oxycodone and trazodone because of the decrease in sodium and its accompanying anions and, in some instances, reduced urea loss (data not shown).

\section{Discussion}

Nocturia is caused either by the delivery of too large a volume of urine for the capacity of the bladder or by the decreased storage ability of the organ. In most elderly people with nocturia, both of these abnormalities exist, and this is illustrated in the present study.

Only 2 medications reduced nocturia: naproxen and oxazepam. Naproxen reduced the volume of urine by $46 \%$ mainly through reduced sodium excretion. As creatinine clearance was unchanged, tubular sodium reabsorption would have to increase, which is shown by the $54 \%$ decrease in the percentage of FENa, less total urine solute and higher osmolality. This effect was similar in magnitude to that described previously in normal volunteers who were given the same dose of naproxen. ${ }^{14}$ With oxazepam, urine volume was unchanged and urine composition was similar to that seen with the other medications. Decreased nocturia could only be the result of improved storage. Because no effect on nocturia was observed with sedatives (zopiclone or trazodone) or analgesics (oxycodone), these cannot be causative in the oxazepam effect. Similarly, both oxazepam and zopiclone yielded perfect sleep scores, yet nocturia with oxazepam was half that with zopiclone. The change in capacity could be a direct effect on the bladder or its nerve supply.

We are aware of only a few studies where a direct effect of BZDs on the human bladder have been examined. In vitro, there was no effect on

Table 2. Urine chemistries, by treatment type*

\begin{tabular}{|c|c|c|c|c|c|c|}
\hline \multirow{2}{*}{$\begin{array}{l}\text { Urine } \\
\text { chemistry }\end{array}$} & \multicolumn{6}{|c|}{ Treatment, mean (SD) $\dagger$} \\
\hline & Placebo & Oxazepam & Zopiclone & Naproxen & Oxycodone & Trazodone \\
\hline Volf, $\mathrm{mL} / \mathrm{min}$ & $1.3(0.6)$ & $1.1(0.4)$ & $1.3(0.4)$ & $0.7(0.4) \S$ & $1.0(0.3)$ & $1.0(0.3) \S$ \\
\hline $\mathrm{Na}, \mathrm{mmol} / \mathrm{Nol}$ & $57.3(7.9)$ & $48.3(12.1) \S$ & $47.3(10.7) \S$ & $25.6(4.7) \S$ & $45.0(8.0) \S$ & $38.0(10.0) \S$ \\
\hline $\mathrm{Na}, \mu \mathrm{mol} / \mathrm{min}$ & $113.7(18.3)$ & $93.3(26.5) \S$ & $94.5(24.0) \S$ & $51.4(8.2) \S$ & $87.5(14.7) \S$ & $72.7(17.4) \S$ \\
\hline FENa, \% & $1.1(0.2)$ & $0.9(0.2) \S$ & $0.9(0.2) \S$ & $0.5(0.1) \S$ & $0.9(0.1) \S$ & $0.7(0.2) \S$ \\
\hline $\mathrm{K}, \mu \mathrm{mol} / \mathrm{min}$ & $52.4(10.6)$ & $42.6(6.2) \S$ & $54.4(12.0)$ & $43.3(10.6) \S$ & $39.9(7.0) \S$ & $49.5(10.0)$ \\
\hline $\mathrm{Cl}, \mu \mathrm{mol} / \mathrm{min}$ & $71.1(11.7)$ & $61.8(22.1)$ & $62.0(18.7)$ & $28.6(6.4) \S$ & $59.6(11.4)$ & $55.2(12.3) \S$ \\
\hline $\mathrm{Ccr}, \mathrm{mL} / \mathrm{min}$ & $71.6(11.7)$ & $71.7(4.8)$ & $74.4(4.3)$ & $71.3(6.5)$ & $69.8(6.1)$ & $69.3(4.3)$ \\
\hline $\begin{array}{l}\text { Osmolality, } \\
\mathrm{mOsm} / \mathrm{kg}\end{array}$ & 538 (195) & $538(148)$ & $497(160)$ & $678(210)$ & $574(141)$ & $579(142)$ \\
\hline Cosm, mL/min & $2.1(0.2)$ & $1.9(0.3)$ & $1.9(0.3)$ & $1.4(0.2) \S$ & $1.8(0.2) \S$ & $1.7(0.3) \S$ \\
\hline \multicolumn{7}{|c|}{$\begin{array}{l}\mathrm{Ccr}=\text { creatinine clearance; } \mathrm{Cl}=\text { chlorine; } \mathrm{Cosm}=\text { osmolar clearance; } \mathrm{FENa}=\text { fractional sodium excretion; } \mathrm{K}=\text { potassium; } \mathrm{Na}=\text { sodium; } \text { Vol = volume. } \\
\text { *Ten tests were performed with each treatment, for a total of } 60 \text { tests. } \\
\text { tUnless otherwise indicated. } \\
\text { †Volume of urine excreted during the night. } \\
\S p<0.05 \text { when compared with placebo. }\end{array}$} \\
\hline
\end{tabular}


isolated detrusor strips when contractions were induced with and without diazepam, although an inhibitory effect was observed in the bladders of rats. ${ }^{15}$ In adults or children there was no effect on bladder parameters when diazepam was administered intramuscularly, ${ }^{16}$ or when the less lipophilic midazolam was administered as a nasal spray. ${ }^{17}$ In comparison to these negative reports, there is extensive animal literature on spinal and supraspinal effects of BZDs, mostly mediated through $\mathrm{GABA}_{\mathrm{A}}$ receptors. ${ }^{18-20}$ Based on this evidence, we would speculatively favour a central effect of oxazepam. Zopiclone also binds to $\mathrm{GABA}_{\mathrm{A}}$ receptors but differs slightly in its effects and profile of receptor subtype binding., 71

The decrease in urine sodium and percentage of FENa, as compared with placebo, was significant for all drugs. In addition, there were similar but less consistent changes for potassium, chloride and osmolar clearance. For naproxen, this is probably a direct effect on the kidney. Opioids are also known to have a renal and a central effect (via $\mu$ receptors) on sodium reabsorption. ${ }^{22,23}$ However, we are unaware of any previous reports relating BZDs, zopiclone or trazodone to electrolyte changes. This effect is therefore either an artifact, which is not in agreement with the data, or more likely a central effect causing antinatriuresis. A decrease in sympathetic output from the forebrain to the kidney, changing tubuloglomerular balance through the juxtaglomerular apparatus, could explain these findings. ${ }^{24,25}$

The strengths of this study are the design and the comparison of multiple drugs. The main weakness is that only 1 person was studied. However, given that the sample is representative of nocturic elderly people, ${ }^{11}$ there is reason to believe that the results are generalizeable in a larger population. In addition the use of a single subject has been validated in several previous studies. ${ }^{10}$

Finally, it may be possible to find among the 1000 or more BZDs that have been synthesized some that have no sedative effect but retain the antinocturic action.

\section{Conclusion}

Nocturia was reduced only by naproxen and oxazepam. The marked sodium retention and decrease in urine output with naproxen and the similarity to previous studies suggests that this result was a direct renal tubular effect. Urine volume was unchanged with oxazepam, and because the other sedatives and analgesics had no effect on nocturia this could not explain the findings with oxazepam. It is suggested that oxazepam was acting through central pathways, either in the spinal cord or higher, causing bladder relaxation, most likely involving GABAergic mechanisms. Aside from naproxen, the other drugs had a small but definite effect in decreasing sodium excretion and reducing the $\mathrm{FENa} \%$. This may be a central effect mediated through the sympathetic nervous system, as suggested previously in a study of circadian weight and sodium excretion in older people. ${ }^{11}$

Professor of Medicine, McGill University (retired), Montréal, Que.

Acknowledgements: I would like to thank J. Konecny, BpH, LpH, for providing the medication; W. Schneider, PhD, for the analyses; L. Joseph, PhD, for statistical advice; E.W. Keyserlingk, LLM, PhD for ethical oversight; Professor K. Krnjevic for his critical comments and manuscript review; and Fernand Chevalot at the Documentation Center, St.Anne's Hospital, for assistance with document retrieval.

This article has been peer reviewed.

Competing interests: None declared.

\section{References}

1. van Kerrebroeck $P$, Abrams $P$, Chaikin D, et al. The standardisation of terminology in nocturia: report from the Standardisation Sub-committee of the International Continence Society. Neurourol Urodyn 2002;00:179-83.

2. Wein A, Lose GR, Fonda D. Nocturia in men, women and the elderly: a practical approach. BJU Int 2002;90(Suppl 3):28-31.

3. Kirkland JL, Lye M, Levy DW, et al. Patterns of urine flow and electrolyte excretion in healthy elderly people. Br Med J (Clin Res Ed) 1983;287:1665-7.

4. Homma Y, Yamaguchi T, Kondo Y, et al. Significance of nocturia in the International Prostate Symptom Score for benign prostate hyperplasia. J Urol 2002;167:172-6.

5. Lichtor JL, Collins VJ. Benzodiazepines, physiologic and pharmacologic bases of anesthesia. Media (PA): Williams and Wilkins; 1996. 527-43,.

6. Fujikawa K, Kasahara M, Matsui Y, et al. Human atrial natriuretic peptide is a useful criterion in treatment of nocturia. Scand I Urol Nephrol 2001;35:310-3.

7. Carlson JN, Haskew R, Wacker J, et al. Sedative and anxiolytic effects of zopiclone's enantiomers and metabolite. Eur J Pharmacol 2001;415:181-9.

8. Ballantyne IC, Mao J. Opioid therapy for chronic pain. N Engl J Med 2003;349:1943-53.

9. Walsh JK, Erman M, Erwin CW, et al. Subjective hypnotic efficacy of trazodone and zolpidem in DSM1 11-R primary insomnia. Hum Psychopharmacol 1998;13:191-8.

10. Guyatt G, Sackett D, Taylor DW, et al. Determining optimal therapy - randomized trials in individual patients. N Engl J Med 1986;314:889-92.

11. Kaye M. Aging, circadian weight change and nocturia. Nephron Physiology 2008;109: 11-18

12. Rose BD, Post TW. Clinical physiology of acid-base and electrolyte disorders. 5th ed. New York: McGraw-Hill; 2001.

13. Dretzke BJ. Statistics with Microsoft Excel. 2nd ed. Upper Saddle River (NJ): Prentice Hall; 2001.

14. Dixey JJ, Noormohamed AF, Lant AF, et al. The effects of naproxen and sulindac on renal function and their interaction with hydrochlorothiazide and piretanide in man. Br J Clin Pharmacol 1987;23:55-63. 
6. Doyle PT, Briscoe CE. The effects of drugs and anaesthetic agents on the urinary bladder and sphincters. Br J Urol 1976;48:329-35.

17. Bozkurt $P$, Kilic N, Kaya $G$, et al. The effects of intranasal midazolam on urodynamic studies in children. Br J Urol 1996;78:282-6.

18. Sillen U, Persson B, Rubenson A. Involvement of central GABA receptors in the regulation of the urinary bladder function of anaesthetized rats. Naunyn Schmiedeberg's Arch Pharmacol 1980;314:195-200.

19. Kontani H, Kawabata Y, Koshiura R. In vivo effects of raminobutyric acid on the urinary bladder contraction accompanying micturition. Jpn J Pharmacol 1987;45:45-53.

20. Kontani $H$, Ueda Y. A method for producing overactive bladder in the rat and investigation of the effects of GABAergic receptor agonists and glutamatergic receptor antagonists on the cystometrogram. J Urol 2005;173:1805-11.

21. Fleck MW. Molecular actions of (S)-desmethylzopiclone (SEP-174559), an anxiolytic metabolite of zopiclone. J Pharmacol Exp Ther 2002;302:612-8.

22. Ellis AG, Adam WR. Effects of opiates on sodium excretion in the isolated perfused rat kidney. Clin Exp Pharmacol Physiol 1991;18:835-42.

23. Danesh S, Walker LA. Effects of central administration of morphine on renal function in conscious rats. Pharmacol Exp Ther 1989;244:640-5.

24. DiBona GF. Dynamic analysis of patterns of renal sympathetic nerve activity: implications for renal function. Exp Physiol 2004;90:159-61.

25. Schnermann J. Juxtaglomerular cell complex in the regulation of renal salt excretion. Am J Physiol 1998;274:R263-79.

Correspondence: Dr. Michael Kaye, 759 Main Rd., Hudson QC JOP 1H0; mkaye@videotron.ca

- For more information on CUA Patient Information Brochures, see page 643.

- Pour plus d'informations concernant les Brochures info-patients de I'AUC, voir à la page 645.

Catheter Care
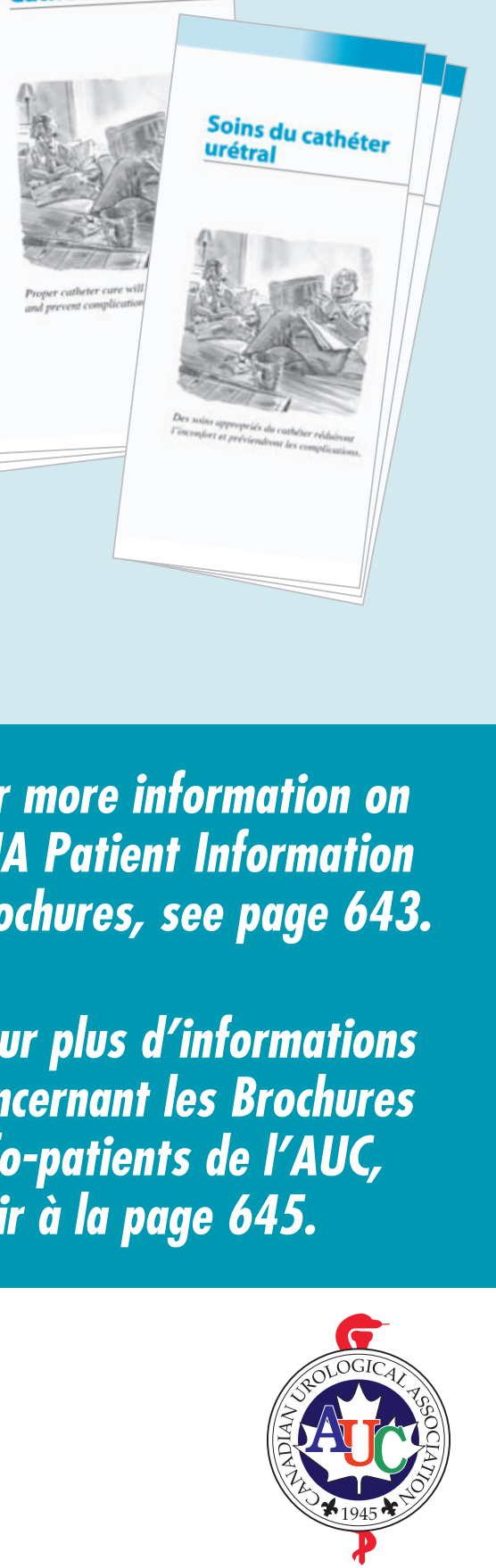